\title{
Stress responses of the fish Nile tilapia subjected to electroshock and social stressors
}

\section{R.E. Barreto and G.L. Volpato}

\author{
Laboratório de Fisiologia e Comportamento Animal, Departamento de Fisiologia, \\ Research Center on Animal Welfare (RECAW), Instituto de Biociências, \\ Universidade Estadual Paulista, Botucatu, SP, Brasil
}

\author{
Correspondence \\ G.L. Volpato \\ Laboratório de Fisiologia e \\ Comportamento Animal \\ Departamento de Fisiologia \\ Instituto de Biociências, UNESP \\ Rubião Jr., s/n \\ 18618-000 Botucatu, SP \\ Brasil \\ Fax: +55-14-3811-6251 \\ E-mail: gilvolp@gmail.com \\ Research supported by FAPESP \\ (No. 00/00070-9).
}

Received January 20, 2006 Accepted September 1, 2006

\begin{abstract}
Plasma cortisol and glucose levels were measured in 36 adult Nile tilapia males, Oreochromis niloticus (standard length, mean $\pm \mathrm{SD}$, $14.38 \pm 1.31 \mathrm{~cm}$ ), subjected to electroshock and social stressors. Prestressor levels were determined 5 days after the adjustment of the fish to the experimental aquaria (1 fish/aquarium). Five days later, the effects of stressors on both cortisol and glucose levels were assessed. The following stressors were imposed for 60 min: pairing with a larger resident animal (social stressor), or a gentle electroshock (AC, $20 \mathrm{~V}$, $15 \mathrm{~mA}, 100 \mathrm{~Hz}$ for 1 min every $4 \mathrm{~min}$ ). Each stressor was tested in two independent groups, one in which stress was quantified immediately after the end of the 60-min stressor imposition (T60) and the other in which stress was quantified 30 min later (T90). Pre-stressor values for cortisol and glucose were not statistically different between groups. Plasma cortisol levels increased significantly and were of similar magnitude for both electroshock and the social stressor (mean \pm SD for basal and final samples were: electroshock $\mathrm{T} 60=65.47 \pm 15.3$, $177.0 \pm 30.3 ; \mathrm{T} 90=54.8 \pm 16.0,196.2 \pm 57.8$; social stress $\mathrm{T} 60=47.1$ $\pm 9.0,187.6 \pm 61.7 ;$ T90 $=41.6 \pm 8.1,112.3 \pm 26.8$, respectively). Plasma glucose levels increased significantly for electroshock at both time points (T60 and T90), but only at T90 for the social stressor. Initial and final mean $( \pm \mathrm{SD})$ values are: electroshock T60 $=52.5 \pm$ $9.2,115.0 \pm 15.7 ; \mathrm{T} 90=35.5 \pm 1.1,146.3 \pm 13.3$; social stress $\mathrm{T} 60=$ $54.8 \pm 8.8,84.4 \pm 15.0 ; \mathrm{T} 90=34.5 \pm 5.6,116.3 \pm 13.6$, respectively. Therefore, electroshock induced an increase in glucose more rapidly than did the social stressor. Furthermore, a significant positive correlation between cortisol and glucose was detected only at T90 for the social stressor. These results indicate that a fish species responds differently to different stressors, thus suggesting specificity of fish stress response to a stressor.
\end{abstract}

\author{
Key words \\ - Stress \\ - Aggression \\ - Agonistic behavior \\ - Fighting \\ - Social stress \\ - Electroshock
}

\section{Introduction}

The biological concept of stress applied to fish has attracted considerable attention in recent years. Stress is a generalized response attributed to the fact that fish commonly have a complex of adaptive reactions to cope with stressors $(1,2)$. For instance, stress has been reported to elevate plasma cortisol (3$8)$, glucose levels $(5,6,9-11)$, and ventilatory 
frequency (12-15) in fish. Although stress can be considered to be a generalized response, it can be modulated by specific stressor conditions (16). Such modifying factors may be either a non-stressor or inherent to the stressor trait. For instance, sexual maturity (4), environmental color $(17,18)$, heritability (7), age (3), and feeding state (8) are non-stressful conditions that modulate the stress response. On the other hand, intensity and duration are stressor characteristics that affect stress $(1,2)$. Most investigations have concentrated on non-stressor factors modulating stressor effects $(19,20)$, and much less emphasis has been placed on differences in fish stress response caused by putative stressor characteristics, which are thus the focus of the present study.

Stressors have been classified for fish as: a) physical factors directly acting on the fish; b) physical stressors with no contact (touching) with the focal animal; c) cues from stressed conspecifics, and d) memory retrieval of a stressful experience (21). Despite this classification, stressful conditions may involve more than one of these types. In view of this possibility, the present study investigated two stressors: electroshock and a social stressor. These stressors are physical since they touch the fish directly. This is because the electricity spreads through the fish body and, during social interactions, a subordinate fish suffers several bites. However, they differ in that electroshock is restricted to the physical contact, with no cue whereby the fish can anticipate the stressor exposure, while a social stressor includes anticipatory psychological components. The presence of a dominant fish is an intimidating threat that can be permanently perceived by the subordinate fish without necessarily involving biting $(16,22)$.

Therefore, in the present study we expected that fish would respond differently to these two stressors (electroshock and social stressors) based on which components are involved (only physical or physical and psy- chological). This latter aspect is also important because it provides preliminary evidence reinforcing the classification of stressors proposed by Moreira and Volpato (21).

On the basis of these considerations, the present study compared fish stress responses to electroshock and a social stressor by measuring plasma levels of cortisol and glucose, two well-established indicators of stress in fish $(1,2)$. We chose the fish species Nile tilapia, Oreochromis niloticus, because it is an important fish model for studying the stress response $(9-13,17,21,23,24)$ and has evident agonistic behavior $(11,12,22,25,26)$, both aspects related to the proposed hypothesis.

\section{Material and Methods}

Fish and holding conditions

Our stock population consisted of 70 adult Nile tilapia males, Oreochromis niloticus (Linnaeus, 1759), acclimated for about one month to an indoor 500-L plastic tank $(\sim 1$ fish/7 L; holding density $\sim 6 \mathrm{~g} / \mathrm{L})$. During this time, the water temperature was $\sim 24^{\circ} \mathrm{C}$, with continuous aeration and systematic recirculation through a biological filter, and the tank was supplied with a constant flow of dechlorinated water. The photoperiod was from 6:00 to $18: 00 \mathrm{~h}$, provided by a fluorescent light (daylight; 350 lux). The fish were fed daily in excess with tropical fish chow (38\% protein; Purina Ltda., Campinas, SP, Brazil).

This research conforms to the Ethical Principles in Animal Research adopted by the Brazilian College of Animal Experimentation and was approved by the Ethics Committee for Animal Research of the Instituto de Biociências de Botucatu, UNESP, SP, Brazil (Protocol No. 97/02).

\section{Experimental design}

The basic design analyzed the effects of 
two types of stressors, electroshock and a social stressor, on plasma cortisol and glucose levels. For the test, 36 fish were matched for size (standard length, mean \pm SD $14.38 \pm$ $1.31 \mathrm{~cm}$ ) and body coloration. Red coloration on the caudal fin of male Nile tilapia indicates sexual maturity (27) and these animals were not used for the present experiment.

The selected fish were randomly assigned to each experimental group. Effects of stressors were studied in socially isolated fish in glass aquaria $(40 \times 20 \times 25 \mathrm{~cm}$, total water volume $20 \mathrm{~L}$; 1 fish per aquarium). Isolation was imposed 10 days before the test. The fish were fed daily in excess (as above), except during the days when they were sampled. The pre-stressor measurements of plasma cortisol and glucose were performed 5 days after the beginning of isolation. Five days later, the same fish were exposed to one of the two stressors (social stressor or electroshock) for $60 \mathrm{~min}$. Post-stress physiological responses were then assessed in two independent groups per stressor: immediately after the end of the 60-min period of stressor imposition (T60) or $30 \mathrm{~min}$ later (T90). Thus, four different groups (9 fish each) were used.

The mean $( \pm$ SD) weights (g) of Nile tilapia were similar among groups: electroshock groups, $\mathrm{T} 60=109.35 \pm 26.21$, T90 $=116.78 \pm$ $32.8 \mathrm{~g}$; social stressor groups, T60 $=98.63 \pm$ $12.5, \mathrm{~T} 90=101.32 \pm 12.27 \mathrm{~g}\left(\mathrm{ANOVA} ; F_{(3 ; 32)}\right.$ $=1.03 ; \mathrm{P}=0.39)$. Mean $( \pm \mathrm{SD})$ standard lengths $(\mathrm{cm})$ were also similar among groups: electroshock groups, T60 = 14.3 \pm 1.5 , T90 = $14.5 \pm 1.7 \mathrm{~cm}$; social stressor groups, T60 = $13.7 \pm 1.0$, T90 = $13.7 \pm 1.2 \mathrm{~cm}($ ANOVA; $\left.F_{(3 ; 32)}=1.18 ; \mathrm{P}=0.33\right)$. Pre- and post-stressor measurements showed no correlation between plasma cortisol or glucose and length or weight.

\section{Stressors}

General conditions. On the test day (10th day of isolation), each fish was transferred to a larger aquarium $(60 \times 28 \times 31 \mathrm{~cm}$, water volume $48 \mathrm{~L}$ ) to be exposed to the stressor. Immediately after $60 \mathrm{~min}$ of stressor imposition, blood samples were obtained from fish of the T60 groups, while the fish of the T90 groups were returned to their respective aquarium for $30 \mathrm{~min}$ before a blood sample was obtained. This aquarium transfer was necessary to impose the social stressor by pairing the focal fish with a resident animal. Thus, the same aquarium transfer was adopted in the electroshock groups to control handling effects.

Social stressor. The social stressor consisted of paring the focal fish with a larger resident fish. The physiological parameters were quantified only in the focal animal, which was the subordinate. The resident larger fish was about $33 \%$ larger than the focal animal (smaller/larger fish ratio (\%): $\mathrm{T} 60=33.71 \pm 4.78$ and $\mathrm{T} 90=33.66 \pm 5.87$; Student $t$-test, $\mathrm{P}=0.98)$. Both previous residence (28) and larger body size (29) are associated with dominance. This procedure guaranteed a clear dominance-subordinance relationship, thus characterizing a typical situation of social stress for the focal fish $(9,11,23,25)$. To evaluate the social stressor, agonistic acts were quantified based on the ethograms described by Alvarenga and Volpato (12), Giaquinto and Volpato (25) and Barki and Volpato (26) for this species.

Aggression was evaluated on the basis of videotape analysis as the frequency of total fights emitted/received by the focal fish and also of each agonistic type emitted by the dominant. This is important to adequately characterize the social stress since the previous history of social interaction modulates the stress response in the Nile tilapia (12). The social ranks of the focal animals were also confirmed by qualitative inspections of the body (9) and/or eye (22) coloration (the eye and body of dominant Nile tilapia fish are pale while those of subordinates are darker).

Electroshock stressor. Electroshock was 
applied with an electric stimulator having two electrodes, each located in the center of the smaller wall of the aquarium. A higher shock might provoke immobilization of and serious injuries to the fish within a few seconds of exposure $(30,31)$. Thus, the shock pattern used here (AC shock with $20 \mathrm{~V}, 15$ $\mathrm{mA}$ and $100 \mathrm{~Hz}$ in water with conductivity of $110 \mu \mathrm{S}$ ) was much weaker compared to those used by Barton and Grosh (5; AC shock with $75 \mathrm{~V}, 3.3 \mathrm{~A}$ ) and Barton and Dwyer (6; DC shock with 120-130 V and 0.5 A). The shock used here only provoked an immediate dorsal fin flick, without any injury or immobilization. Therefore, we imposed the electroshock for a longer time, i.e., $1 \mathrm{~min}$ every $4 \mathrm{~min}$ for $1 \mathrm{~h}$.

\section{Aquarium conditions}

The experimental aquaria were supplied with continuous aeration and equipped with a biological filter (recirculating water system). During the experiments the water temperature was $\sim 23^{\circ} \mathrm{C}, \mathrm{pH}$ ranged from 6.2 to 6.5 , oxygen concentrations were near saturation $(\sim 7.5 \mathrm{mg} / \mathrm{L})$, nitrite and ammonia were lower than 0.5 and $0.25 \mathrm{ppm}$, respectively, and salinity was $0.0 \mathrm{ppm}$. Photoperiod and illumination were as in the holding condition, but light was about 480 Lux.

\section{Blood collection, sample processing, and cortisol and glucose analyses}

Blood was always sampled (pre- and poststressor collections) at 11:00 h. For blood collections, each fish was netted and individually anesthetized with $80 \mathrm{mg} / \mathrm{L}$ of benzocaine by bath exposure, and blood (about $400 \mu \mathrm{L}$ ) was then sampled by cardiac puncture using heparinized syringes (Liquemine ${ }^{\circledR}$, Roche, Rio de Janeiro, RJ, Brazil). Blood sampling never lasted more than 1 min per fish. Blood was centrifuged (3000 rpm for $10 \mathrm{~min}$ ) and plasma (about $100 \mu \mathrm{L}$ ) was collected, transferred to 1-mL capped tubes, and stored frozen $\left(-22^{\circ} \mathrm{C}\right)$ until required for assay.

Plasma cortisol levels were determined by a routine technique using a commercial kit for radioimmunoassay, "Coat-a-Count Cortisol ${ }^{\circledR}$ " - DPC (Diagnostic Products Corporations, Los Angeles, CA, USA). Plasma glucose levels were determined by the colorimetric method of Trinder (32).

\section{Statistical analysis}

Plasma cortisol and glucose data showed normal distribution by the KolmogorovSmirnov test. ANOVA (completely randomized design) was employed to compare treatments under pre-stressor conditions. Mean post-stressor cortisol and glucose levels were compared with pre-stressor levels by the paired Student $t$-test, and between stressors at each time point by the independent Student $t$-test. The Pearson test was used to assess the correlation between post-stressor cortisol and glucose levels. The frequency of the agonistic interactions and the agonistic profile were assessed by the Mann-Whitney U-test and Friedman test. The level of significance was set at $\alpha=0.05$.

\section{Results}

No statistical difference was observed between the attacks received and emitted by focal fish at T60 and T90 (Mann-Whitney U-test, $\mathrm{P}=0.83$ and 0.81 , respectively). Focal fish received an expressive number of attacks, $233.6 \pm 180.5$ (T60 group) and 185.7 \pm 98.1 (T90 group), showing that social stress was evident. Moreover, focal animals emitted very few attacks, $3.3 \pm 4.9$ (T60 group) and $4.7 \pm 6.7$ (T90 group), clearly showing their submissive status. Thus, in the subsequent analysis, due to the reduced frequency of attacks emitted by the focal fish, we considered only the attacks received by them. No significant difference in the mean frequency of each agonistic pattern was de- 
tected between the T60 and T90 groups (Mann-Whitney U-test, lowest $\mathrm{P}=0.12$; Figure 1). Nipping at the medial body area of the opponent was the most frequent agonistic pattern displayed, while the other patterns were similar to each other (Friedman test; T60 and T90, $\mathrm{P}<0.0001$; Figure 1). Thus, the intensity of the social stressor in terms of attacks was similar for the T60 and T90 groups.

Mean baseline levels for both cortisol and glucose were statistically similar among groups (Figure 2; ANOVA; cortisol, $F_{(3 ; 32)}=$ $0.69, \mathrm{P}=0.57$; glucose, $F_{(3 ; 32)}=2.18, \mathrm{P}=$ $0.10)$. Electroshock and social stressor increased fish cortisol levels when compared with their pre-stressor state (paired Student $t$-test; electroshock: T60, $\mathrm{P}<0.01$; T90, $\mathrm{P}<$ 0.05 , and social stressor: T60, $\mathrm{P}<0.05$; T90, $\mathrm{P}<0.05)$. However, the same profile was not observed for glucose levels. Glucose was increased significantly by electroshock at both time points (paired Student $t$-test; T60, $\mathrm{P}<0.05$, and T90, $\mathrm{P}<0.0001)$ compared to the pre-stressor situation, while for the social stressor glucose was increased only at T90 (paired Student $t$-test; T60, $\mathrm{P}=0.19$, and $\mathrm{T} 90, \mathrm{P}<0.0001$ ). In addition, no difference was found between electroshock and social stressor for glucose (independent Student $t$-test; $\mathrm{T} 60, \mathrm{P}=0.23$, and $\mathrm{T} 90, \mathrm{P}=0.13$ ) or cortisol levels (independent Student $t$ test; T60, $\mathrm{P}=0.89$, and $\mathrm{T} 90, \mathrm{P}=0.21$ ) at each time point.

In the electroshock series, no correlation was detected at all (Figure 3), with very low correlation coefficients for both $\mathrm{T} 60\left(\mathrm{R}^{2}=\right.$ $0.0064 ; \mathrm{P}=0.83)$ and T90 $\left(\mathrm{R}^{2}=0.0001 ; \mathrm{P}=\right.$ $0.98)$. The social stressor, however, imposed a different profile (Figure 3), with no significant correlation at $\mathrm{T} 60$, but with a high $\mathrm{R}^{2}\left(\mathrm{R}^{2}=\right.$ $0.3969 ; \mathrm{P}=0.07)$, and with a significant correlation at T90 $\left(\mathrm{R}^{2}=0.5476 ; \mathrm{P}<0.05\right)$.

\section{Discussion}

The present study indicated that different

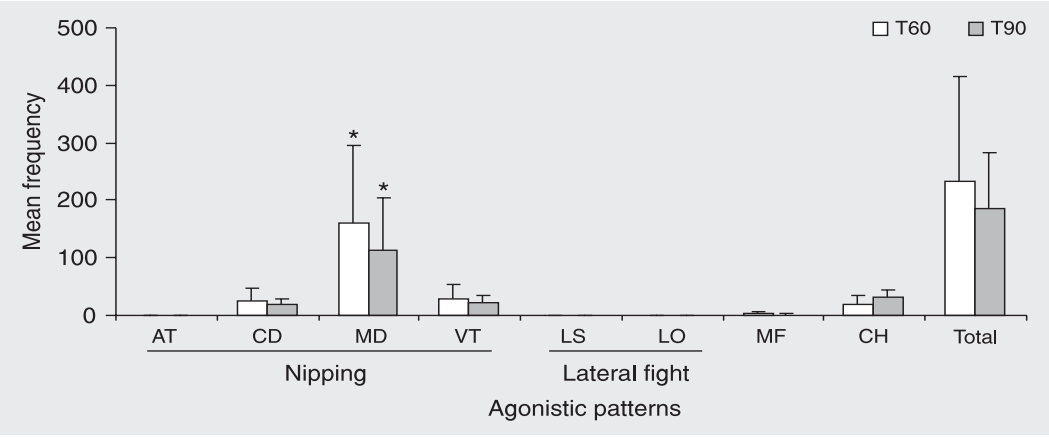

Figure 1. Mean frequency of agonistic interaction patterns received by the focal Nile tilapia. Nipping: $\mathrm{AT}=$ anterior, $\mathrm{CD}=$ caudal, $\mathrm{MD}=$ median, and $\mathrm{VT}=$ ventral area; lateral fight: $\mathrm{LS}=$ fish in the same direction, $\mathrm{LO}=$ fish in opposite directions; $\mathrm{MF}=$ mouth fight; $\mathrm{CH}=$ chasing. T60 are fish that had blood collected after the end of the 60-min period of stressor imposition; in T90 blood was collected 30 min later (includes $60 \mathrm{~min}$ of stressor plus $30 \mathrm{~min}$ later). "Median nipping within both T60 and T90 groups was the most frequent agonistic pattern (Friedman test; $\mathrm{P}<0.0001$ ), while the remaining ones were similar to each other. No difference was observed when each pattern was compared between the T60 and T90 groups (Mann-Whitney test; lowest $P$ value $=0.12$ ).
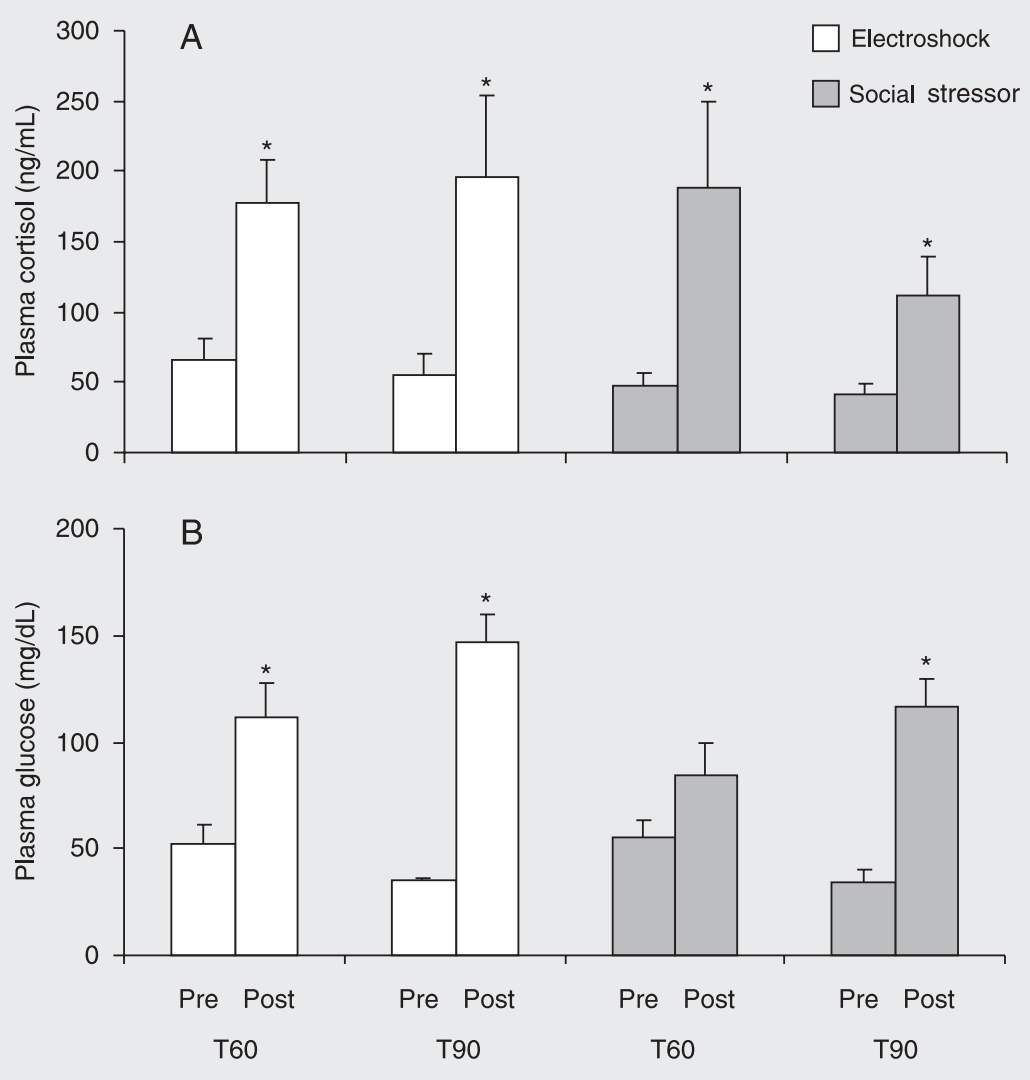

Figure 2. Pre- and post-plasma cortisol (A) and glucose (B) levels in the Nile tilapia exposed to electroshock or to a social stressor. Note that the left side of the Figure refers to T60 and the right side to T90. See legend to Figure 1 for identification of T60 and T90. ${ }^{*} \mathrm{P}<0.05$ compared to the respective pre-stressor level (paired Student $t$-test). 
stressors cause distinct stress responses in the Nile tilapia fish, thus reinforcing the specificity of stress in fish. Electroshock induced a faster increase in plasma glucose levels compared with the response obtained to the social stressor. In addition, cortisol and glucose levels were only correlated with each other for the social stressor. This effect provides some evidence corroborating the classification of stressors proposed by Moreira and Volpato (21), as they differ from each other by the presence of the psychological component in the social stressor.

The initial analysis considers the adequacy of pre-stressor measurements of plasma cortisol and glucose levels. Mean pre-stressor cortisol levels ranged from 41.57 to $65.67 \mathrm{ng} / \mathrm{mL}$ (Figure 2), in agreement with other studies. For instance, the baseline described for $O$. niloticus ranged from $\sim 5$ to $60 \mathrm{ng} / \mathrm{mL}(10,11,17,23,24)$, and for the related Cichlid, O. mossambicus, it ranged from $\sim 20$ to $60 \mathrm{ng} / \mathrm{mL}$ (33), and from about 10 to 60 for other fish species $(3-6,19,34)$.

Figure 3. Pearson correlations between post-stressor plasma cortisol and glucose levels in the Nile tilapia subjected to electroshock and to a social stressor. Different fish were sampled for each stressor and time point $(\mathrm{N}=9$ in each case). See legend to Figure 1 for identification of T60 and T90. Significant correlation occurred only for social stressor at T90, and thus linear regression is shown in this case.

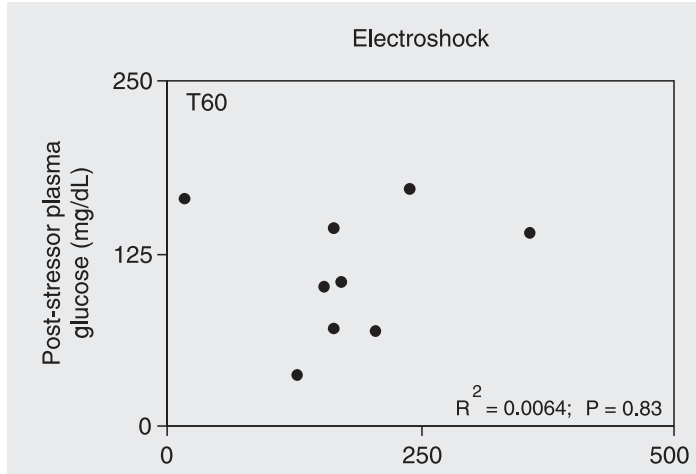

Plasma glucose fluctuated from 34.54 to $52.45 \mathrm{mg} / \mathrm{dL}$, within the range previously reported for the Nile tilapia, from 45 to 130 $\mathrm{mg} / \mathrm{dL}(9,10,35)$, and for other species, from $\sim 40$ to $110 \mathrm{mg} / \mathrm{dL}(5,6)$. These data confirm the non-stressed baseline for the fish in the present study.

Electroshock and social stressors induced an elevation in plasma cortisol levels at a similar rate in the Nile tilapia for both time points (T60 and T90). However, while electroshock significantly increased plasma glucose levels at both time points, social stressor increased plasma glucose only at T90. These results clearly show that electroshock induces a glucose response more rapidly than social stress in the Nile tilapia. Methodologically, it is difficult to provide stressful conditions of equivalent intensity. However, the magnitude of the cortisol response represents a suitable parameter for the comparative goal of the present study. The magnitudes of the cortisol levels observed here suggest similar intensity of the stressors.
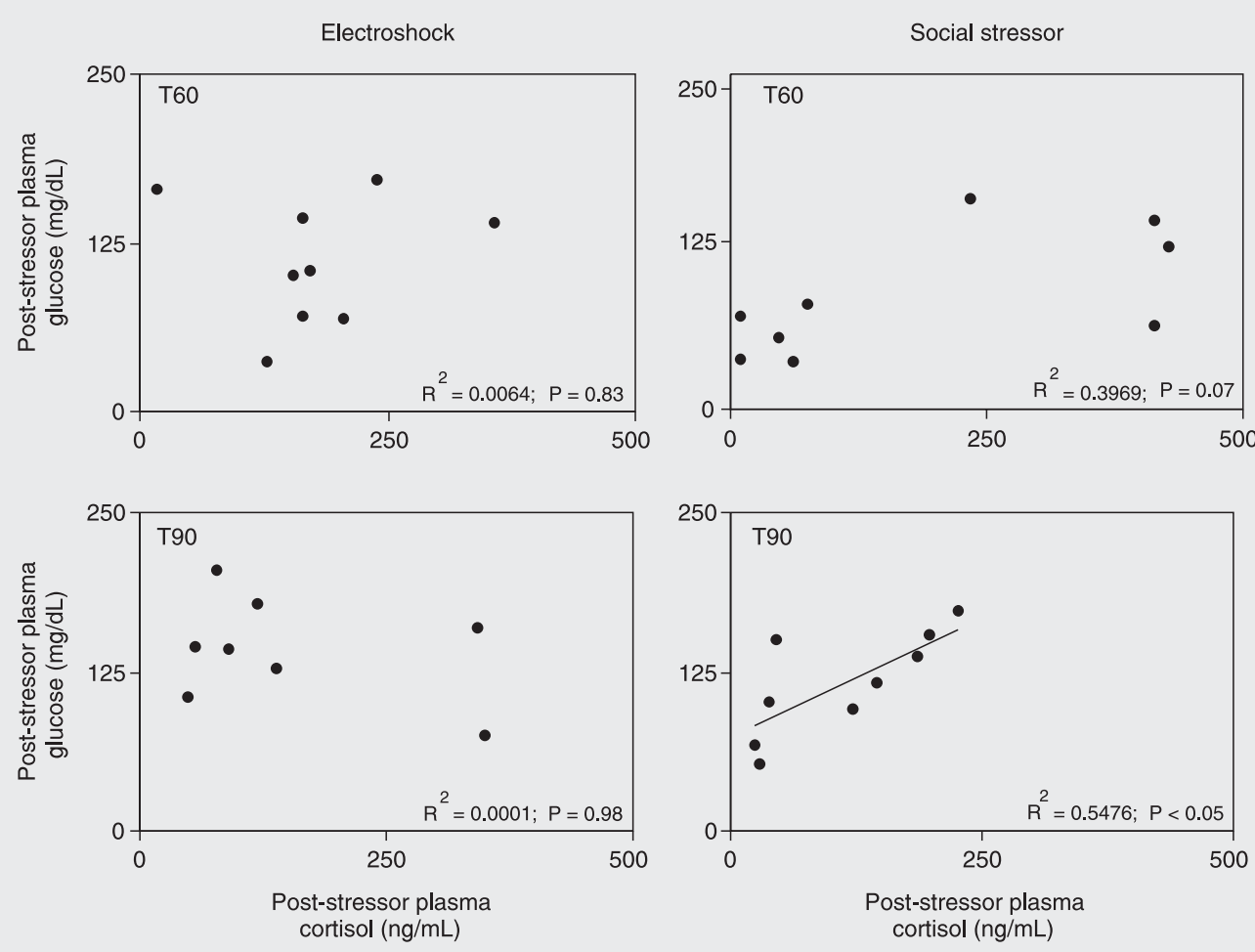
Thus, the difference found for the glucose response in this species depends more probably on stressor modalities than on intensity. A similar conclusion has been reported for rats in terms of distinct reproductive steroid hormone responses to different stressors with a similar magnitude of corticosteroid response among stressors (36). Moreover, Nile tilapia also presents a difference in its ventilatory responses when subjected to different stressors (14).

The idea of a distinct stress response to different stressor modalities is reinforced by the significant correlation between cortisol and glucose only for social stressors (Figure 3). A similar correlation between cortisol and glucose for social stress has been previously reported for the Nile tilapia (11), but the present study indicates the role of stressor modality in this relationship.

This stressor modality-dependent effect could indicate different mechanisms underlying the control of glucose levels. Although the determination of the mechanisms involved in the glucose response is beyond the scope of the present study, the correlation analyses shown in Figure 3 indicate that such mechanisms may also be stressor related. The significant correlation between cortisol and glucose (social stressor, T90) in contrast to a clear absence of correlation for electroshock at the same time point strongly suggests the dependence of the stressor modality on the mechanisms controlling glu- cose levels. Cortisol is usually considered to have a hyperglycemic effect (37) and, indeed, it has been reported that fish exposed to increased levels of cortisol had increased glucose levels (33), which could explain the significant correlation described herein. However, electroshock-exposed fish increased glucose without a correlated cortisol increase, thus suggesting that other factors are involved. This suggestion should be clarified in future investigations, also because controversial results have been reported regarding cortisol-regulated glucose levels: cortisol was reported to decrease (38) or not to affect (39) glucose levels, and Trenzado et al. (40) reported that low-cortisol responding rainbow trout had higher glucose increase than high-cortisol responding fish.

\section{Acknowledgments}

The authors thank Mr. A.C.B. Tardivo, Mr. H.L. Silva, Ms. A.T. Robiero, Dr. L. Faine, Dr. L.C. Jordão, and Dr. J.A. Almeida for very helpful technical assistance; Dr. L.M.R. Muniz (Department of Animal Reproduction and Veterinary Radiology, FMVZ, UNESP/Botucatu, SP, Brazil) for allowing the cortisol analyses to be carried out in her laboratory; Dr. E.L.B. Novelli (Department of Biochemistry, IB, UNESP/Botucatu, SP, Brazil) for allowing the glucose analyses to be carried out in her laboratory; Dr. F.A.N.F. Chubaci for monitoring the electroshock output.

\section{References}

1. Bonga SEW. The stress response in fish. Physiol Rev 1997; 77: 591-625.

2. Barton BA. Stress in fishes: A diversity of responses with particular reference to changes in circulating corticosteroids. Integr Comp Biol 2002; 42: 517-525.

3. Pottinger TG, Mosuwe E. The corticosteroidogenic response of brown and rainbow trout alevins and fry to environmental stress during a "critical period". Gen Comp Endocrinol 1994; 95: 350-362.

4. Pottinger TG, Balm PH, Pickering AD. Sexual maturity modifies the responsiveness of the pituitary-interrenal axis to stress in male rainbow trout. Gen Comp Endocrinol 1995; 98: 311-320.

5. Barton BA, Grosh RS. Effects of AC electroshock on blood features in juvenile rainbow trout. J Fish Biol 1996; 49: 1330-1333.

6. Barton BA, Dwyer WP. Physiological stress effects of continuousand pulsed-DC electroshock on juvenile bull trout. J Fish Biol 1997; 51: 998-1008.

7. Pottinger TG, Carrick TR. Modification of the plasma cortisol response to stress in rainbow trout by selective breeding. Gen Comp Endocrinol 1999; 116: 122-132.

8. Pottinger TG, Rand-Weaver M, Sumpter JP. Overwinter fasting and 
re-feeding in rainbow trout: plasma growth hormone and cortisol levels in relation to energy mobilisation. Comp Biochem Physiol B Biochem Mol Biol 2003; 136: 403-417.

9. Fernandes MO, Volpato GL. Heterogeneous growth in the Nile tilapia: social stress and carbohydrate metabolism. Physiol Behav 1993; 54: 319-323.

10. Barcellos LJG, Nicolaiewsky S, Souza SMG, Lulhier F. Plasmatic levels of cortisol in the response to acute stress in Nile tilapia Oreochromis niloticus (L.), previously exposed to chronic stress. Aquac Res 1999; 30: 437-444.

11. Correa SA, Fernandes MO, Iseki KK, Negrao JA. Effect of the establishment of dominance relationships on cortisol and other metabolic parameters in Nile tilapia (Oreochromis niloticus). Braz J Med Biol Res 2003; 36: 1725-1731.

12. Alvarenga $\mathrm{CM}$, Volpato GL. Agonistic profile and metabolism in alevins of the Nile tilapia. Physiol Behav 1995; 57: 75-80.

13. Barreto RE, Volpato GL. Caution for using ventilatory frequency as an indicator of stress in fish. Behav Processes 2004; 66: 43-51.

14. Barreto RE, Volpato GL. Ventilatory frequency of Nile tilapia subjected to different stressors. J Exp Anim Sci 2006; 43: 189-196.

15. Brown C, Gardner C, Braithwaite VA. Differential stress responses in fish from areas of high- and low-predation pressure. J Comp Physiol [B] 2005; 175: 305-312.

16. Zayan R. The specificity of social stress. Behav Processes 1991; 25: 81-93.

17. Volpato GL, Barreto RE. Environmental blue light prevents stress in the fish Nile tilapia. Braz J Med Biol Res 2001; 34: 1041-1045.

18. Van der Salm AL, Martínez M, Flik G, Bonga SEW. Effects of husbandry conditions on the skin colour and stress response of red porgy, Pagrus pagrus. Aquaculture 2004; 241: 371-386.

19. Barton BA, Peter RE. Plasma cortisol response in fingerling rainbow trout, Salmo gairdineri Richardson, to various transport conditions, anesthesia, and cold shock. J Fish Biol 1982; 20: 39-51.

20. Frisch AJ, Anderson TA. Physiological stress responses of two species of coral trout (Plectropomus leopardus and Plectropomus maculatus). Comp Biochem Physiol A 2005; 140: 317-327.

21. Moreira PS, Volpato GL. Conditioning of stress in Nile tilapia. J Fish Biol 2004; 64: 961-969.

22. Volpato GL, Luchiari AC, Duarte CR, Barreto RE, Ramanzini GC. Eye color as an indicator of social rank in the fish Nile tilapia. Braz $J$ Med Biol Res 2003; 36: 1659-1663.

23. Barcellos LJ, Nicolaiewsky S, Souza SM, Lulhier F. The effects of stocking density and social interaction on acute stress response in Nile tilapia Oreochromis niloticus (L.) fingerlings. Aquac Res 1999; 30: 887-892.

24. Biswas AK, Maita M, Yoshizaki G, Takeuchi T. Physiological responses in Nile tilapia exposed to different photoperiod regimes. $J$ Fish Biol 2004; 65: 811-821.
25. Giaquinto PC, Volpato GL. Chemical communication, aggression, and conspecific recognition in the fish Nile tilapia. Physiol Behav 1997; 62: 1333-1338.

26. Barki A, Volpato GL. Early social environment and the fighting behaviour of young Oreochromis niloticus (Pisces, Cichlidae). Behaviour 1998; 135: 913-929.

27. Gonçalves-de-Freitas E, Nishida SM. Sneaking behaviour of the Nile tilapia. Boletim Técnico do CEPTA 1998; 11: 71-79.

28. Chellappa S, Yamamoto ME, Cacho M, Huntingford FA. Prior residence, body size and the dynamics of territorial disputes between male freshwater angelfish. J Fish Biol 1999; 55: 1163-1170.

29. Turner GF, Huntingford FA. A problem for game theory analyses: assessment and intention in male mouth brooder contests. Anim Behav 1986; 34: 961-970.

30. Dwyer WP, Shepard BB, White RG. Effect of backpack electroshock on west slope cutthroat trout injury and growth 110 and 250 days post-treatment. N Am J Fish Manage 2001; 21: 646-650.

31. Dolan CR, Miranda LE. Injury and mortality of warm water fishes immobilized by electrofishing. N Am J Fish Manage 2004; 24: 118127.

32. Trinder $P$. Determination of blood glucose using an oxidase-peroxidase system with a non-carcinogenic chromogen. J Clin Pathol 1969; 22: 158-161.

33. Vijayan MM, Pereira C, Gordon-Grau E, Iwama GK. Metabolic responses associated with confinement stress in tilapia: the role of cortisol. Comp Biochem Physiol C 1997; 116: 89-95.

34. Carneiro PCF, Urbinati EC. Transport stress in matrinxa, Brycon cephalus (Teleostei: Characidae), at different densities. Aquac Int 2002; 10: 221-229.

35. Yavuzcan HY, Pulatsu S, Kurtoglu F. Baseline of haematological and serological parameters of healthy Nile tilapia. Anim Sci Pap Rep 1997; 15: 213-217.

36. Andersen ML, Bignotto M, Machado RB, Tufik S. Different stress modalities result in distinct steroid hormone responses by male rats. Braz J Med Biol Res 2004; 37: 791-797.

37. Mommsen TP, Vijayan MM, Moon TW. Cortisol in teleosts: dynamics, mechanisms of action, and metabolic regulation. Rev Fish Biol Fish 1999; 9: 211-268.

38. Vijayan MM, Ballantyne JS, Leatherland JF. Cortisol-induced changes in some aspects of the intermediary metabolism of Salvelinus fontinalis. Gen Comp Endocrinol 1991; 82: 476-486.

39. Vijayan MM, Pereira C, Moon TW. Hormonal-stimulation of hepatocyte metabolism in rainbow-trout following an acute handling stress. Comp Biochem Physiol C 1994; 108: 321-329.

40. Trenzado CE, Carrick TR, Pottinger TG. Divergence of endocrine and metabolic responses to stress in two rainbow trout lines selected for differing cortisol responsiveness to stress. Gen Comp Endocrinol 2003; 133: 332-340. 